ORIGINAL ARTICLE

\title{
The prevalence and characteristics associated with parent- infant bed-sharing in England
}

\section{P S Blair, H L Ball}

See end of article for authors' affiliations

.....................

Correspondence to: Dr P S Blair, FSID Research Department, Division of Child Health, Education Building, Upper Maudlin St, Bristol BS2 8AE, UK; p.s.blair@bris.ac.uk

Accepted 2 February 2004

Aims: To investigate the characteristics of parent-infant bed-sharing prevalence in England. Methods: Data on night-time sleeping practices from a two year, local, longitudinal study and a threeyear, national, cross-sectional study were obtained. A total of 261 infants in North Tees were followed up at 1 and 3 months of age, as were 1095 infants aged 1 week to 1 year from five English health regions. Results: Data from both studies found that almost half of all neonates bed-shared at some time with their parents (local $=47 \%, 95 \% \mathrm{Cl} 41$ to 54 ; national $=46 \%, 95 \% \mathrm{Cl} 34$ to 58 ), and on any one night in the first month over a quarter of parents slept with their baby (local $=27 \%, 95 \% \mathrm{Cl} 22$ to 33 ; national $=30 \%, 95 \%$ $\mathrm{Cl} 20$ to 42). Bed-sharing was not related to younger mothers, single mothers, or larger families, and was not more common in the colder months, at weekends, or among the more socially deprived families; in fact bed-sharing was more common among the least deprived in the first months of life. Breast feeding was strongly associated with bed-sharing, both at birth and at 3 months. Bed-sharing prevalence was uniform with infant age from 3 to 12 months; on any one night over a fifth of parents (national $=21 \%, 95 \% \mathrm{Cl} 18$ to 24) slept with their infants.

Conclusion: Bed-sharing is a relatively common practice in England, not specific to class, but strongly related to breast feeding.

A though physical contact between parents and infants during sleep is culturally widespread, ${ }^{1}$ the debate about parent-infant bed-sharing in Western societies has polarised around benefits of prolonged contact, and concern that this environment may introduce risks to infants..$^{2-3}$ Some argue that all parent-infant bed-sharing should be banned to prevent the proportionately small number of infant deaths that occur in adult beds; ${ }^{2}$ however others caution against throwing the baby out with the bathwater, ${ }^{4-5}$ and that recommendations about bed-sharing cannot be made without empirical data based on further research. ${ }^{6-8}$

Bed-sharing was initially implicated as a risk factor for sudden infant death syndrome (SIDS); ${ }^{9}$ however it subsequently became clear that smoking and alcohol were confounding variables. ${ }^{10}$ Furthermore in populations where bed-sharing is normative practice, but other risk factors are absent, cot death rates are unusually low. ${ }^{11-13}$

As very little data exist on bed-sharing prevalence in Western industrial societies, this paper reports such data from England. Using a precise definition of bed-sharing we compare two data sets to examine characteristics of this practice over time; a local two year longitudinal study of night-time infant care practices in northeast England and, as part of the Confidential Enquiry into Stillbirths \& Deaths in Infancy (CESDI), a national cross-sectional case-control study into the causes of SIDS which included control data on bed-sharing on a particular night.

\section{METHODS}

Centred on the Borough of Stockton-on-Tees, the North Tees Night-time Parenting Study examined normal night-time parenting of families with young infants. The total population was 178000 (mid-2000), with 2097 live births per year (1998). Thirty per cent of households were classified "low income" (1998), with Stockton ranking 49th most deprived borough of 353 in the UK index of Local Deprivation. ${ }^{14}$

Using sleep logs and interviews we obtained information on night-time care-giving for a broadly representative sample of 261 families with a newborn infant. ${ }^{15}$ Two families had twins and we use data here from the firstborn only. Participants completed structured diaries (sleep logs) regarding night-time parenting for one week during the infant's first and third months of life.

CESDI was a three year (February 1993 to March 1996) population based case-control study encompassing five former health regions (South West, Trent, Yorkshire, Northern, and Wessex). The population was 17.7 million, with 473000 live-births within these regions during the study. Data were obtained by parental interviews for all SIDS deaths and four surviving control infants. The age matched controls were randomly chosen from the caseload of the health visitor of the index infant. As previously reported, ${ }^{16}$ $92.5 \%$ of the control families approached were used for this study; a comparison of maternal occupation with GB census data from 1991 suggested that this sample was broadly representative of the larger maternal population. A period of sleep (the "reference sleep") was identified 24 hours before the control interview corresponding to the time of day during which the index baby had died. Any details of the infant sleep were therefore not subject to more than 24 hours recall bias. Details of night-time sleeps were recorded for 1095 of the 1300 controls. These infants were used to look at the age distribution of bed-sharing from birth to 12 months; subgroups of these infants (63 aged less than a month and 176 infants 3-4 months of age) were used to look at other aspects of bed-sharing. Seven control families had twins; again data were used from the firstborn only.

Differences in proportions have been tested with the $\chi^{2}$ test using Yates's correction; Fisher's exact test has been used when any cell had an expected value $<5$. All tests were two tailed with a 5\% degree of significance. Non-normal distributions have been described using medians and interquartile ranges (IQR). Confidence intervals for single proportions were based on the Wilson method. ${ }^{17}$

Bed-sharing was defined by taking a specific night and calculating the proportion of infants who slept with an adult 
Table 1 Demographic characteristics of infants and families in the local and national studies

\begin{tabular}{|c|c|c|c|c|c|c|}
\hline & \multicolumn{2}{|c|}{ Local study (North Tees) } & \multicolumn{2}{|c|}{ National study (CESDI) } & \multirow{2}{*}{$\begin{array}{l}\chi^{2 *} \\
\text { (n df) }\end{array}$} & \multirow[b]{2}{*}{$\mathrm{p}$ value } \\
\hline & $n / N$ & (\%) & $n / N$ & (\%) & & \\
\hline \multicolumn{7}{|l|}{ Infant factors } \\
\hline Sex (boys) & $134 / 259$ & (51.7) & $571 / 1095$ & (52.1) & 0.00 (1df) & 0.96 \\
\hline Multiple birth & $3 / 259$ & $(1.2)$ & $7 / 1095$ & $(0.6)$ & - & $0.41 \dagger$ \\
\hline Birth weight $<2.5 \mathrm{~kg}$ & $5 / 259$ & $(1.9)$ & $55 / 1087$ & $(5.1)$ & $4.10(1 \mathrm{df})$ & 0.04 \\
\hline Gestation $<37$ weeks & $10 / 233$ & (4.3) & $59 / 1083$ & $(5.4)$ & 0.31 (ldf) & 0.58 \\
\hline Attempted to breast feed & $150 / 249$ & $(60.2)$ & $651 / 1095$ & (59.5) & 0.02 (1df) & 0.87 \\
\hline \multicolumn{7}{|l|}{ Family factors } \\
\hline \multicolumn{7}{|l|}{ Maternal } \\
\hline Age $<21$ years & $32 / 259$ & (12.4) & $111 / 1095$ & $(10.1)$ & 0.97 (1df) & 0.33 \\
\hline Marital status (single) & $13 / 253$ & (5.1) & $57 / 1095$ & $(5.2)$ & 0.01 (1df) & 0.91 \\
\hline Ethnicity (non-white) & $6 / 259$ & (2.3) & $70 / 1095$ & $(6.4)$ & $5.82(1 \mathrm{df})$ & 0.02 \\
\hline Parity $>3 \ddagger$ & $14 / 259$ & $(5.4)$ & $81 / 1095$ & $(7.4)$ & 0.99 (1df) & 0.32 \\
\hline No waged income & $30 / 246$ & (12.2) & $208 / 1094$ & (19.0) & $5.93(1 \mathrm{df})$ & 0.02 \\
\hline \multicolumn{7}{|l|}{ Socioeconomic status§ } \\
\hline I/II & $79 / 240$ & (32.9) & $351 / 1093$ & (32.1) & $5.32(2 d f)$ & 0.07 \\
\hline $\mathrm{IIIm} / \mathrm{n}$ & $82 / 240$ & (34.2) & $451 / 1093$ & (41.3) & & \\
\hline $\mathrm{IV} / \mathrm{V} / \mathrm{U}$ & $79 / 240$ & (32.9) & $291 / 1093$ & $(26.6)$ & & \\
\hline
\end{tabular}

Characteristics of the CESDI infants aged up to 1 month $(N=63)$ and $3-4$ months $(N=176)$ were similar to the group as a whole.

*Using Yates's corrected value.

†Fisher's exact test.

flncluding child in the study.

$\S$ Based on the Registrar General's Occupational Coding using highest parental classification (I= professional to U = unemployed).

for at least part of the sleep. For the local study this meant randomly choosing a night from the sleep log; for the national study this meant using the information collected for the "reference sleep" in the previous 24 hours. Usual practice was recorded, but a scale of response was taken rather than a dichotomy; measuring the time spent in the parental bed over an average week was used by the local study, while obtaining responses from "never" to "always bed-sharing" from the parents was the method used by the national study. Because of the cross-sectional nature of the national study, data on usual practice were only obtained for infants aged up to 1 month; otherwise it was difficult to distinguish in which age range the usual practice applied.

\section{RESULTS}

Table l compares the demographic characteristic for the two study populations. Many of the infant factors were similar between the two groups. Infant birth weight was slightly different, but this is probably explained by the fact that recruitment for the local study excluded particularly small infants under intensive care. Many of the family factors were also similar; unemployment and non-white families were more prevalent in the national study, but more of the North Tees families were classified in the lower social stratum.

Table 2 shows that $47 \%$ of the neonates in the local study bed-shared with their parents at least once, for all or part of the night (median age at start of sleep log week $=13$ days, IQR 7-22). In the national study parents responded that $46 \%$ of neonates had bed-shared at least occasionally during this period (median age $=20$ days, IQR 17-25). The prevalence of bed-sharing during the 3-4 month period (median age $=98$ days, IQR 91-106) fell to $30 \%$ in the local study; there were no comparable data available from the national study.

Table 2 Parent-infant bed-sharing prevalence during night sleep in the 1st and 3rd-4th month of infancy

\begin{tabular}{|c|c|c|c|c|}
\hline & \multicolumn{2}{|c|}{ Local study (North Tees) } & \multicolumn{2}{|c|}{ National study (CESDI) } \\
\hline & $n / N$ & Prevalence $\left(95 \% \mathrm{Cl}^{*}\right)$ & $\mathrm{n} / \mathrm{N} \dagger$ & Prevalence $\left(95 \% \mathrm{Cl}{ }^{*}\right)$ \\
\hline \multicolumn{5}{|c|}{ Usual practice } \\
\hline \multicolumn{5}{|c|}{ Bed-shared in 1 st month } \\
\hline Occasionally & $31 / 253$ & $12 \%$ & $13 / 63$ & $21 \%$ \\
\hline Often & $53 / 253$ & $21 \%$ & $8 / 63$ & $13 \%$ \\
\hline All the time & $36 / 253$ & $14 \%$ & $8 / 63$ & $13 \%$ \\
\hline In total & $120 / 253$ & $47 \%$ (41\% to $54 \%$ ) & $29 / 63$ & $46 \%$ (34\% to $58 \%)$ \\
\hline \multicolumn{5}{|c|}{ Bed-shared in 3rd-4th month } \\
\hline Occasionally & $18 / 248$ & $7 \%$ & - & \\
\hline Often & $37 / 248$ & $15 \%$ & - & \\
\hline All the time & $19 / 248$ & $8 \%$ & - & \\
\hline In total & $74 / 248$ & $30 \%(25 \%$ to $36 \%)$ & - & \\
\hline \multicolumn{5}{|c|}{$\begin{array}{l}\text { On a particular night } \\
\text { Bed-shared in } 1 \text { st month }\end{array}$} \\
\hline Part of sleep & $54 / 261$ & $21 \%$ & $14 / 63$ & $22 \%$ \\
\hline All of the sleep & $16 / 261$ & $6 \%$ & $5 / 63$ & \\
\hline In total & $70 / 261$ & $27 \%$ (22\% to $33 \%)$ & $19 / 63$ & $30 \%(20 \%$ to $42 \%)$ \\
\hline \multicolumn{5}{|c|}{ Bed-shared in 3rd-4th month } \\
\hline Part of sleep & $10 / 251$ & $4 \%$ & $22 / 176$ & $13 \%$ \\
\hline All of sleep & $29 / 251$ & $12 \%$ & $13 / 176$ & $7 \%$ \\
\hline In total & $39 / 251$ & $16 \%(12 \%$ to $21 \%)$ & $35 / 176$ & $20 \%(15 \%$ to $26 \%)$ \\
\hline
\end{tabular}


Table 3 Relation between infant bed-sharing on a specific night and demographic characteristics

\begin{tabular}{|c|c|c|c|c|c|c|c|c|c|c|c|c|}
\hline & \multicolumn{6}{|c|}{ Neonatal infants } & \multicolumn{6}{|c|}{ Infants aged 3-4 months } \\
\hline & \multicolumn{2}{|c|}{ Bed-shared* } & \multicolumn{2}{|c|}{ Not bed-shared } & \multirow[b]{2}{*}{$\chi^{2} \dagger$} & \multirow[b]{2}{*}{ p value } & \multicolumn{2}{|c|}{ Bed-shared* } & \multicolumn{2}{|c|}{ Not bed-shared } & \multirow[b]{2}{*}{$\chi^{2} \dagger$} & \multirow[b]{2}{*}{$\mathrm{p}$ value } \\
\hline & $n / N$ & $\%$ & $n / N$ & $\%$ & & & $n / N$ & $\%$ & $n / N$ & $\%$ & & \\
\hline \multicolumn{13}{|l|}{ Infant factors } \\
\hline Sex (boys) & $45 / 84$ & 54 & $118 / 227$ & 52 & 0.01 (1df) & 0.90 & $46 / 74$ & 62 & $170 / 350$ & 49 & 3.99 (1df) & 0.046 \\
\hline Multiple birth & $3 / 84$ & 4 & $1 / 227$ & 0.4 & - & $0.06 \ddagger$ & $1 / 73$ & 1 & $3 / 348$ & 0.9 & - & $0.53 \ddagger$ \\
\hline Birth weight $<2.5 \mathrm{~kg}$ & g $2 / 82$ & 2 & $9 / 212$ & 4 & - & $0.73 \ddagger$ & $4 / 73$ & 5 & $9 / 334$ & 3 & - & $0.26 \ddagger$ \\
\hline $\begin{array}{l}\text { Gestation } \\
<37 \text { weeks }\end{array}$ & $5 / 80$ & 6 & $10 / 211$ & 5 & - & $0.57 \ddagger$ & $2 / 72$ & 3 & $19 / 335$ & 6 & - & $0.55 \ddagger$ \\
\hline $\begin{array}{l}\text { Attempted to breast } \\
\text { feed }\end{array}$ & $73 / 84$ & 87 & $113 / 227$ & 50 & $33.6(1 \mathrm{df})$ & $<0.0001$ & $58 / 74$ & 78 & $202 / 350$ & 58 & 3.17 (1df) & 0.08 \\
\hline \multicolumn{13}{|l|}{ Family factors } \\
\hline \multicolumn{13}{|l|}{ Maternal } \\
\hline Age $<21$ y & $7 / 84$ & 8 & $29 / 225$ & 13 & 0.83 (1df) & 0.36 & $9 / 73$ & 12 & $38 / 350$ & 11 & 0.03 (1df) & 0.87 \\
\hline $\begin{array}{l}\text { Marital status } \\
\text { (single) }\end{array}$ & $4 / 84$ & 5 & $22 / 225$ & 10 & 1.40 (1df) & 0.24 & $5 / 73$ & 7 & $27 / 350$ & 8 & 0.00 (1df) & 0.99 \\
\hline $\begin{array}{l}\text { Ethnicity (non- } \\
\text { white) }\end{array}$ & $6 / 83$ & 7 & $10 / 225$ & 4 & - & $0.39 \ddagger$ & $3 / 73$ & 4 & $17 / 348$ & 5 & - & $1.00 \ddagger$ \\
\hline $\begin{array}{l}\text { Parity }>3 \S \\
\text { S.e.c. status }\end{array}$ & $2 / 84$ & 2 & $15 / 226$ & 7 & - & $0.17 \ddagger$ & $3 / 73$ & 4 & $24 / 350$ & 7 & - & $0.60 \ddagger$ \\
\hline I/II & $38 / 81$ & 47 & $74 / 217$ & 34 & 4.34 (2df) & 0.11 & 29/71 & 41 & $124 / 342$ & 36 & $6.21(2 d f)$ & 0.04 \\
\hline $\mathrm{IIIm} / \mathrm{n}$ & $25 / 81$ & 31 & $89 / 217$ & 41 & & & $32 / 71$ & 45 & $122 / 342$ & 36 & & \\
\hline IV/V/U & $18 / 81$ & 22 & $54 / 217$ & 25 & & & 10/71 & 14 & $96 / 342$ & 28 & & \\
\hline No waged income & $8 / 82$ & 10 & $18 / 220$ & 8 & 0.04 (1df) & 0.84 & $4 / 72$ & 6 & $44 / 345$ & 13 & $2.36(1 \mathrm{df})$ & 0.12 \\
\hline
\end{tabular}

Both studies also report the snapshot prevalence of bedsharing on a particular night. Choosing a random night from the local study sleep logs showed $27 \%$ of infants bed-shared in the first month, while $16 \%$ did so in the third month. The prevalence in the national study was slightly higher; $30 \%$ of parents were bed-sharing with infants aged up to 1 month and $20 \%$ when the infant was aged 3-4 months (median age $=97$ days, IQR 90 to 104).

Combining data from the local and national studies, table 3 illustrates how the characteristics listed in table 1 were associated with infant bed-sharing. There was no gender preference among parents bed-sharing with neonates, however by 3-4 months of age there was a higher prevalence of male infants bed-sharing and this statistically significant discrepancy continued in older infants; $65 \%$ (62/96) of the infants aged 4-12 months who were bed-sharing in the national study were male. Neither pre-term nor low birth weight infants were more likely to bed-share. Breast feeding was strongly associated with bed-sharing among neonatal infants and their mothers. It is relevant to note that $46 \%$ (34/
74) of bed-sharing mothers and infants were still breast feeding at 3-4 months, twice as many as those mothers and infants sleeping apart $(23 \%, 81 / 350)$, a highly significant difference $\left(\chi^{2}=14.94,1 \mathrm{df}, \mathrm{p}<0.0001\right)$.

The prevalence of bed-sharing among non-white ethnic groups was not significantly different but the numbers in these studies were very small. There was no evidence that younger mothers, single mothers, or mothers of larger families were more likely to bed-share. Among neonates bed-sharing was more prevalent among the least deprived social classes and at 3-4 months of age this discrepancy reached statistical significance. However this finding may be specific to early infancy as there was no socioeconomic difference with bed-sharing infants between 4 and 12 months of age in the National study.

Figure 1 shows a breakdown of bed-sharing on a particular night by age in the national study. The decrease in bedsharing observed in table 2 from birth to 3 months is clearly evident; however there is no further decrease after this period. At 9-12 weeks $21 \%$ of infants were bed-sharing for at

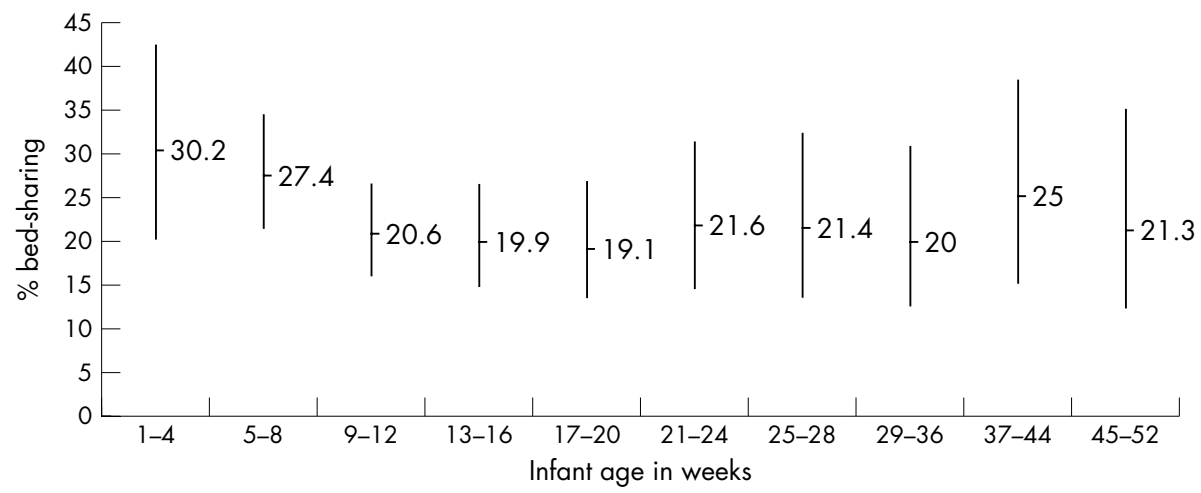

Figure 1 Bed-sharing on a specific night by infant age (prevalence every four weeks with $95 \% \mathrm{Cls}$ ). National CESDI study.

$\mathrm{N}$ for each age range: $63,175,223,176,131,88,70,39,31,31,21,24,23$ 


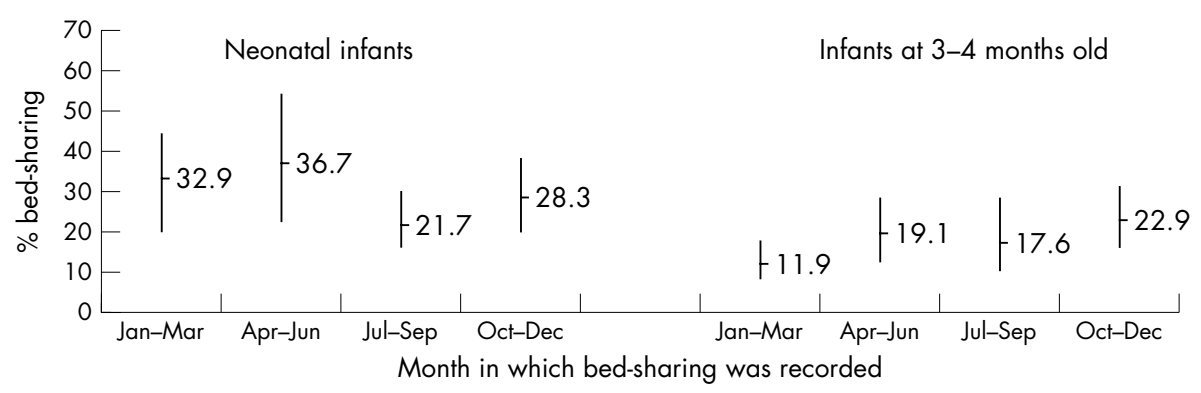

Figure 2 Bed-sharing on a specific night by month (neonates and infants at 3-4 months) (prevalence in three month blocks with $95 \% \mathrm{Cls}$ ). Data from national and local studies combined.

$\mathrm{N}$ for each category:

Neonatal infants $=73,30,129,92$

Infants at 3-4 months old $=151,89,68,118$

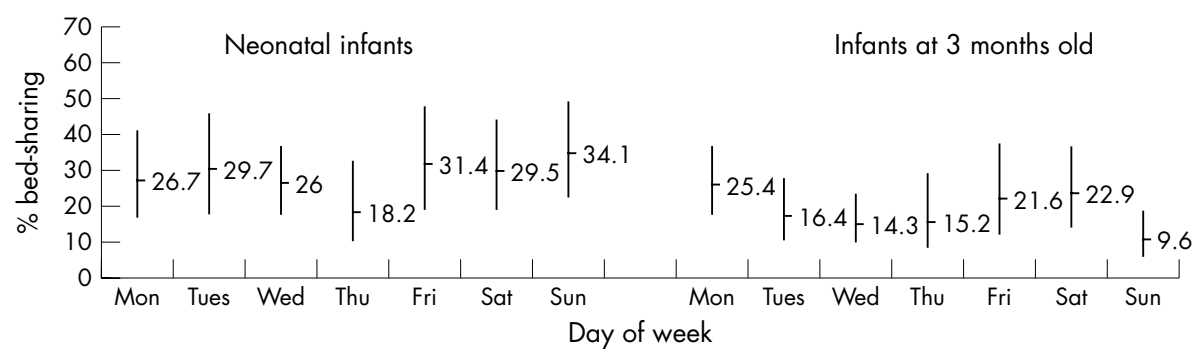

Figure 3 Bed-sharing on a specific night by day (neonates and infants at 3 months) (prevalence with $95 \% \mathrm{Cls}$ ). Data on national and local studies combined.

$\mathrm{N}$ for each day:

Neonatal infants $=45,37,77,44,35,44,41$

Infants at 3 months old $=71,61,91,4$

least part of the sleep on any one particular night; from 13 to 52 weeks this proportion was also $21 \%$ (95\% CI 18-24\%).

In order to determine whether there was a seasonal effect on the prevalence of bed-sharing we combined data on trimonthly prevalence from both studies for bed-sharing among neonates and when infants were 3-4 months of age (fig 2). There was no seasonal effect among neonatal infants $\left(\chi^{2}=4.53,3 \mathrm{df}, \mathrm{p}=0.21\right)$, nor at $3-4$ months of age $\left(\chi^{2}=5.68,3 \mathrm{df}, \mathrm{p}=0.12\right)$.

We also examined whether bed-sharing prevalence fluctuated on a daily basis (fig 3). Despite a slight mid-week dip, no significant difference in the prevalence of bed-sharing at the weekends (Friday and Saturday) compared to weekdays (Sunday to Thursday) was found in either neonates or 34 month old infants.

\section{DISCUSSION}

We base our calculations of bed-sharing prevalence on quantitative criteria involving a designated sleep night. This avoids the problems associated with defining the dichotomy of "usual practice" which forces parents into categorising their infant's predominant sleeping behaviour and generally produces a severe underestimation of prevalence. ${ }^{18}$ The findings from the two independent studies described here, that nearly $50 \%$ of neonates in England bed-share at least occasionally, support each other, although both estimates may be conservative. The local study did not record cases where occasional bed-sharing occurred at a frequency of less than once per week while the national study excluded infants less than a week old when bed-sharing is at its peak. One of the few previous English studies, conducted in southeast England, reported $44 \%$ of infants had bed-shared in a nominated two week period. ${ }^{19}$ Estimates of bed-sharing prevalence in other westernised countries appear to yield similar high proportions. A recent study from the USA reported that among predominantly low income inner-city families $48 \%$ of infants regularly bed-shared at 3-7 months of age and a similar proportion continued to do so up to one year of age, ${ }^{20}$ while a large study in New Zealand determined that $43 \%$ of infants recently bed-shared at 3 months of age. ${ }^{21}$

Bed-sharing prevalence on a selected night will obviously be much smaller than over a selected period of time, but it was surprising in both studies reported here how many parents bed-shared on the designated night. The findings suggest that in England on any particular night more than a quarter of parents will be bed-sharing with their neonatal infant for some part of their sleep and that at least a fifth of parents will be bed-sharing with older infants. This supports findings from a small longitudinal study conducted in Adelaide $^{22}$ which showed a slightly higher prevalence of bed-sharing among younger infants (2-12 weeks of age) compared to older infants (13-24 weeks of age), but a relatively constant distribution of bed-sharing prevalence over the first six months of an infant's life. Our data did not show a seasonal effect in bed-sharing prevalence or a significant weekend effect.

Breast feeding mothers commonly bed-share as a means to ameliorate the disruption of nocturnal breast feeding, ${ }^{23}{ }^{24}$ thus we should expect that breast feeders will predominate in any population of bed-sharers; an expectation confirmed in both the local and national studies discussed here. Both the prevalence of bed-sharing among breast feeding mothers, and the benefits of bed-sharing to breast feeding mothers and infants, indicate that common sense safety advice regarding bed-sharing, rather than outright prohibition, would be of benefit to the majority of parents and babies. ${ }^{6} 24$

In several countries both ethnicity and deprived socioeconomic class have been associated with bed-sharing prevalence. ${ }^{26}$ Results from this study suggest that bedsharing is prevalent across the social strata in England, if not more common among the least deprived stratum. 


\section{Conclusion}

The characteristics of bed-sharing parents and infants generated from these two studies of English families depict bed-sharing as a widespread night-time infant care-giving behaviour, strongly associated with breast feeding with a uniform post-neonatal prevalence not strongly related to socioeconomic status. These findings do not reflect those found in other Western industrialised nations where bedsharing is characterised as an infant care-giving strategy practiced by certain deprived ethnic and socioeconomic groups. It is important, therefore, that assumptions regarding bed-sharing prevalence and circumstance are not extrapolated from the international literature and applied indiscriminately in discussions of bed-sharing in England.

\section{ACKNOWLEDGEMENTS}

Grant bodies for the national study include funds from (1) National Advisory Body for the Confidential Enquiry into Stillbirths and Deaths in Infancy (CESDI), (2) the Foundation for the Study of Infant Deaths (FSID), and (3) Babes in Arms. The Local North Tees Night-time Parenting Study was also funded by the Foundation for the Study of Infant Deaths and supported by the North Tees Health Trust. Both authors would like to thank the parents and infants who generously took part in these studies.

\section{Authors' affiliations}

P S Blair, FSID Research Department, Division of Child Health, University of Bristol, Bristol, UK

H L Ball, Infancy and Childhood Research Group, Department of Anthropology, University of Durham, Durham, UK

\section{REFERENCES}

1 Barry H, Paxson LM. Infancy and early childhood: cross-cultural codes 2. Ethnology 1971;10:466-508

2 Nakamura S, Wind M, Danello MA. Review of hazards associated with children placed in adult beds. Arch Pediatr Adolesc Med 1999:153:1019-23.

3 Drago DA, Dannenberg AL. Infant mechanical suffocation deaths in the united states, 1980-1997. Pediatrics 1999;103:1-8.

4 McKenna JJ. Cultural influences on infant and childhood sleep biology, and the science that studies it: toward a more inclusive paradigm. In: Loughlin JMC, Carroll J, eds. Sleep in development and pediatrics. New York: Marcel Dekker, 2000
5 Kelley C. Pediatric forum: Should infants sleep with their parents? Arch Pediatr Adolesc Med 2000;154:1171-3.

6 Sugrue T. Bedsharing and cot death [letter]. N Z Med J 1995;108:324

7 O'Hara M, Harruff R, et al. Sleep location and suffocation: how good is the evidence? [letter]. Pediatrics 2000;105(4 pt 1):915-17.

8 Blair PS, Fleming PJ, et al. Babies sleeping with parents: case-control study of factors influencing the risk of the sudden infant death syndrome. BMJ 1999;319:1457-60

9 Mitchell EATBJ, Ford RP, Stewart A, et al. Four modifiable and other major risk factors for cot death; the New Zealand study. J Paediatr Child Health 1992;28(suppl 1):S3-8

10 Scragg R, Mitchell EA, et al. Bed sharing, smoking, and alcohol in the sudden infant death syndrome. BMJ 1993;307:1312-18.

11 Balarajan R, Raleigh VS, Botting B. Sudden infant death syndrome and postneonatal mortality in immigrants in England and Wales. BMJ 1989;298:716-20.

12 Watanabe N, Yotsukura M, Kadoi N, et al. Epidemiology of sudden infant death syndrome in Japan. Acta Paediatrica Japan 1994:36:329-32.

13 Nelson EAS, Chan PH. Child care practices and cot death in Hong Kong N Z Med J 1996; 109:144-6

14 Office of the Deputy Prime Minister. 1998 Index of Local Deprivation-Local Authority District Scores and Values on 12 Indicators, http:// www.urban.odpm.gov.uk/research/98ild/.

15 Ball HL. Reasons to bed-share: why parents sleep with their infants. Journal of Reproductive and Infant Psychology 2002;20:207-22.

16 Leach CEA, Blair PS, Fleming PJ, et al. Sudden unexpected deaths in infancy: similarities and differences in the epidemiology of SIDS and explained deaths. Pediatrics 1999;104:e43.

17 Altman DG, Machin D, Bryant T, et al. Statistics with confidence, 2nd edn. London: BMJ Books, 1989:46-8.

18 Hiley CMH, Morley CJ. Evaluation of government's campaign to reduce risk of cot death. BMJ 1994;309:703-4.

19 Esmail A, Lambert PC, et al. Prevalence of risk factors for sudden infant death syndrome in South East England before the 1991 national 'back to sleep' health education campaign. J Public Health Med 1995;17:282-9.

20 Brenner RA, Simons-Morton BG, Bhaskar B, et al. Infant parent bedsharing in an inner city population. Arch Pediatr Adolesc Med 2003; 157:33-9.

21 Tuohy PG, Smale P, et al. Ethnic differences in parent/infant co-sleeping practices in New Zealand. N Z Med J 1998;111:364-6.

22 Rigda RS, McMillen IC, Buckley P. Bed sharing patterns in a cohort of Australian infants during the first six months after birth. J Paediatr Child Health 2000;36:117-21

23 Ball HL. Breastfeeding, bed-sharing and infant sleep. Birth 2003;30:181-8.

24 Byard R. Is breast feeding in bed always a safe practice? J Paediatr Child Health 1998;34:418-19.

25 Servan-Schreiber D. Sleep location and suffocation: how good is the evidence? Pediatrics 2000;105:919-20.

26 Willinger M, Ko CW, Hoffman $\mathrm{HJ}$, et al. Trends in infant bed-sharing in the United States, 1993-2000: National Infant Sleep Position study. Arch Pediatr Adolesc Med 2003; 157:43-9.

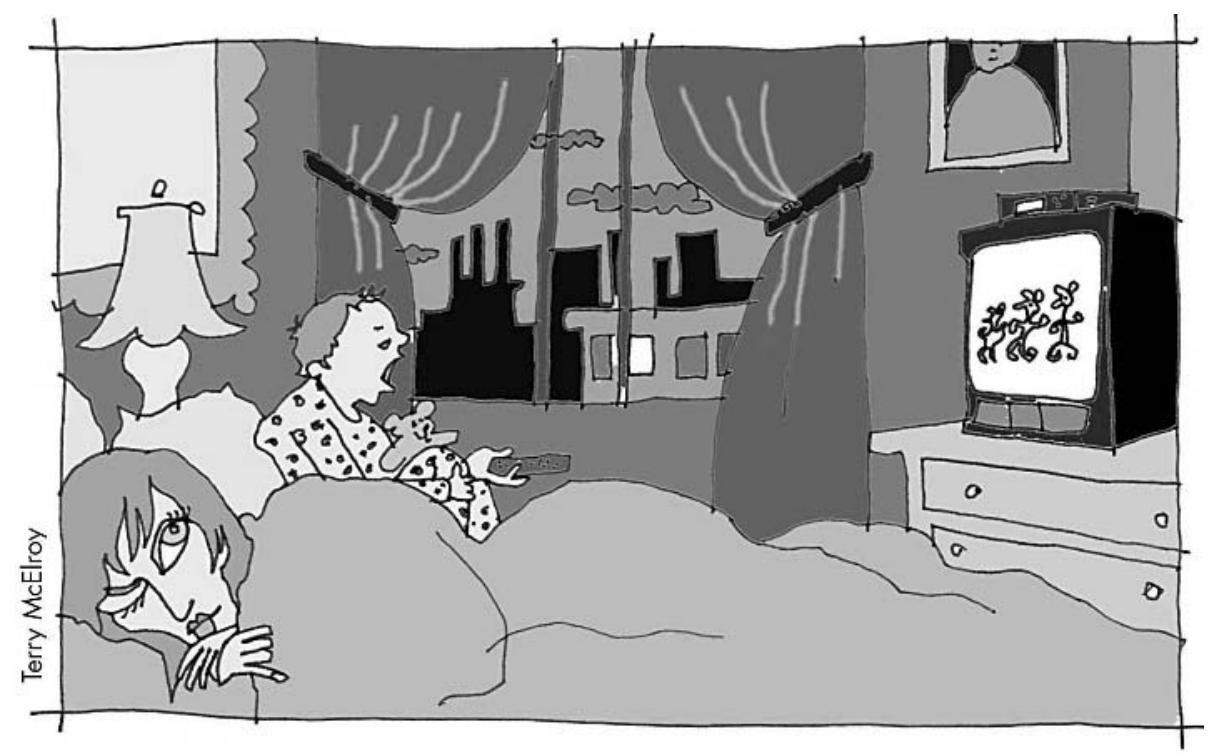

